occasions and to and fro movement of the fluid in the lower oesophagus.

Twenty patients had both barium and ultrasound examinations as described above. There was agreement on 18 examinations; 7 patients showed reflux and 11 showed no abnormality on either examination. One patient had definite reflux on ultrasound examination but 'minimal' reflux was reported on the radiographic examination. On the 16 year old patient, reflux was seen on the barium swallow but it was not possible to outline the oesophagus on ultrasound because of interposition of lung between the heart and the aorta.

\section{Discussion}

We had observed that some infants and children had a line of 'bright' echoes behind the heart during two dimensional echocardiographic examinations. Closer scrutiny showed that these echoes represented fluid filled oesophagus caused by occasional reflux. This prompted us to undertake the present study to assess the possibility of diagnosing reflux using ultrasound.

It became obvious after the first few examinations that the method was as accurate and in some ways superior to the barium swallow. Ultrasound examination is likely to be more physiological as it is not necessary to use contrast media and infants are now examined after normal feeds. It is also more accurate than the barium examination in which one uses very short radiographic screening time to minimise the radiation dose. This leads to false negative examinations in $15 \%$ of cases. $^{2}$ With ultrasound it is possible to scan continuously for several seconds and the examination may be carried out over several minutes (usually 15 minutes) by intermittent scanning. Gastro-oesophageal reflux may be reliably diagnosed by ultrasound but resolution of anatomical detail is generally insufficient to allow comment upon the presence or absence of an associated hiatus hernia. Only two of 20 patients in this study were over 3 years of age so the application in older children remains to be assessed.

Most radiology departments have real time ultrasound equipment for neonatal head and abdominal examinations. A sector scanner is probably the equipment of choice for this, as for all paediatric ultrasound examinations.

New diagnostic modalities are often criticised for providing some additional information but not replacing established techniques. In our department, ultrasound examination has replaced conventional barium examinations in all cases of suspected gastro-oesophageal reflux in children and is also used in follow up of children receiving antireflux treatment. In addition to avoiding unnecessary exposure to radiation, there are undoubted savings in the use of contrast media and $x$-ray films that have important implications if all infants presenting with near-miss sudden infant death syndrome are to be screened for reflux. Ultrasound is a safe, reliable, and rapid method of diagnosing reflux.

We thank our consultant paediatrician colleagues, particularly Dr A Boon.

\footnotetext{
References

' MacFadyen UM, Hendry GMA, Simpson H. Gastrooesophageal reflux in near-miss sudden infant death syndrome or suspected recurrent aspiration. Arch Dis Child 1983;58: 87-91.

${ }^{2}$ Herbst JJ. Gastro-oesophageal reflux. J Pediatr 1981;98:859-70.
}

Correspondence to Dr D J Moore, Northern General Hospital, Sheffield S5 7AU.

Received 28 November 1983

\title{
Serum immunoglobulin concentrations in febrile convulsions
}

\author{
D ISAACS, A D B WEBSTER, AND H B VALMAN
}

\author{
Departments of Paediatrics and Immunology, Northwick Park Hospital and Clinical \\ Research Centre, Harrow
}

SUMmary The mean, age adjusted, serum IgA values of 47 children with febrile convulsions were almost identical to those of controls. Five children had serum $\operatorname{IgA}$ values less than $0 \cdot 1 \mathrm{~g} / \mathrm{l}$ by nephelometry, suggesting that in some cases at least there may be an association between a low serum IgA concentration and febrile convulsions.
A distinction is drawn between selective $\operatorname{IgA}$ deficiency and low serum $\operatorname{IgA} .^{1}$ In selective $\operatorname{IgA}$ deficiency, serum IgG and IgM values are normal but serum $\operatorname{IgA}$ is undetectable by radial immunodiffusion $(<0.02 \mathrm{~g} / \mathrm{l})$. In low serum $\operatorname{IgA}$, serum $\operatorname{IgA}$ can be detected by radial immunodiffusion but is more than two standard deviations below the mean for age. 
It has been suggested that low serum IgA values in childhood may be associated with an increased susceptibility to febrile convulsions..$^{2-4}$ This suggestion has not been adequately tested because of the difficulty in obtaining reference ranges for serum immunoglobulins in children and the inaccuracy of many reference ranges used. ${ }^{5}$ We have recently developed a reference range for serum immunoglobulins derived from sera from 298 healthy children attending infant welfare clinics and schools in the Harrow area. ${ }^{5}$ An unexpected finding was that serum immunoglobulin concentrations in childhood are not $\log$ normally distributed, and formulas were derived to convert the raw data to normal distribution, to allow calculation of reference ranges. ${ }^{5}$

We compare serum immunoglobulin values from 47 children presenting with febrile convulsions, with the predicted, age matched values obtained from our reference ranges.

\section{Materials and methods}

Venous blood $(1 \mathrm{ml})$ was obtained from 47 children presenting consecutively to the paediatric department with a simple convulsion associated with fever greater than $38^{\circ} \mathrm{C}$, and who were being venesected for other investigations. Children already on anticonvulsant medication were excluded, as anticonvulsants are known to lower serum IgA values. Serum immunoglobulin values were determined using a Hyland laser nephelometer PDQ system as previously described. ${ }^{5}$ Sera from children with serum IgA less than $0.1 \mathrm{~g} / \mathrm{l}$ by nephelometry were also tested by double antibody radioimmunoassay. ${ }^{6}$ This study was approved by the Northwick Park Hospital ethical committee.

\section{Results}

Serum IgG, IgA, and IgM values of all 47 children with febrile convulsions fell within the $95 \%$ reference ranges calculated from sera from 298 healthy children. ${ }^{5}$ Only the serum $\operatorname{IgA}$ values are shown in the accompanying Figure. The five children who had serum $\operatorname{IgA}$ less than $0 \cdot 1 \mathrm{~g} / \mathrm{l}$ by nephelometry, all had IgA detectable by immunoassay (greater than 0.03 $\mathrm{g} / \mathrm{l}$ ). They are shown on the Figure as $\operatorname{IgA}=0.05 \mathrm{~g} / \mathrm{l}$ and analysed as such statistically. As the lower limit of normal serum $\operatorname{IgA}$ in our reference range is below $0 \cdot 1 \mathrm{~g} / \mathrm{l}$ until 26 months of age and as all five children were below this age, none could be considered as definitely having low serum $\operatorname{IgA}$.

Analysis of the immunoglobulin values were performed by transforming each value to the scale in which the data were normally distributed using the

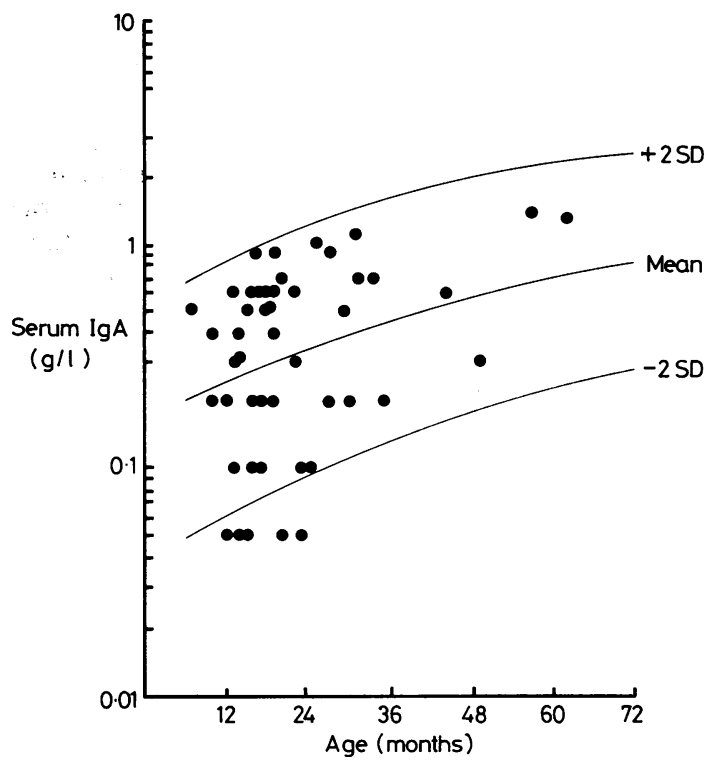

Figure Serum IgA values for 47 children with febrile convulsions.

The reference range, mean (2SD) is shown. Children with serum IgA less than $0 \cdot 1 \mathrm{~g} / \mathrm{l}$ are shown as $0 \cdot 05 \mathrm{~g} / \mathrm{l}$.

Table Analysis of age specific SD scores for children with febrile convulsions

\begin{tabular}{llllll}
\hline Immunoglobulin & No & Mean & $S D$ & $t$ & $P$ \\
\hline IgG & 47 & 0.14 & 0.89 & 1.06 & 0.29 \\
IgA & 47 & 0.05 & 1.31 & 0.26 & 0.80 \\
IgM & 47 & 0.25 & 0.90 & 1.89 & $0 \cdot 06$ \\
\hline
\end{tabular}

equations previously described. ${ }^{5} \mathrm{~A}$ standard deviation score (SDS) was calculated,

where SDS $=\frac{\text { observed value-mean value }}{\text { standard deviation }}$.

The mean and standard deviation of the SDS value was tested against zero by a one sample $t$ test, and the results are shown in the accompanying Table.

\section{Discussion}

Seager et al discussed the possibility of an association between IgA deficiency and febrile convulsions because, of the 32 children with afebrile seizures that they studied, five of the 15 who presented initially with febrile convulsions had low serum IgA values. ${ }^{2}$ 
Their criteria for low serum $\operatorname{Ig}$ A were, however, based on a reference range from a different laboratory.

In attempting to analyse the relation between febrile convulsions and $\operatorname{IgA}$ deficiency two approaches are possible, one of which would be to examine the incidence of febrile convulsions in a group of children with low serum IgA or selective IgA deficiency and compare this with a control population. An alternative approach is to measure IgA values in a group of children presenting with febrile convulsions and compare these with a reference range, and this has been our method. Lewis $e t$ al performed a similar study on 49 children presenting with febrile convulsions, ${ }^{3}$ but again used a reference range from another laboratory. Our study shows no difference between mean age adjusted IgA values from 47 children with febrile convulsions and a large normal population, but five children had serum IgA less than $0.1 \mathrm{~g} / \mathrm{l}$ by nephelometry. It may be that in some children low serum $\operatorname{IgA}$ is associated with susceptibility to febrile convulsions.
We thank the staff of the Haematology Department, Mr H Ip, D G Altman, Dr M M Liberman, and Dr T Stacey. This work was supported by the Medical Research Council.

References

' Savilahti E. Pelkonen P. Clinical findings and intestinal immunoglobulins in children with partial IgA deficiency. Acta Paediatr Scand 1979:68:513-9.

${ }^{2}$ Seager J, Jamison DL. Wilson J. Hayward AR. Soothill JF. IgA deficiency, epilepsy and phenytoin treatment. Lancet $1975 ;$;i: $632-5$.

${ }^{3}$ Lewis HM, Valman HB, Webster ADB, Tyrell DAJ. Viruses in febrile convulsions (letter). Lancet 1980;ii:150.

${ }^{4}$ Asherson GL, Webster ADB. Diagnosis and treatment of immunodeficiency diseases. Oxford: Blackwell Scientific Publications, 1980.

'Isaacs D, Altman DG, Tidmarsh CE, Valman HB, Webster ADB. Serum immunoglobulin concentrations in pre-school children measured by laser nephelometry: reference ranges for IgG. IgA and IgM. J Clin Pathol 1983;36:1193-6.

6 DeGast G-C, Platts-Mills TAE. Functional studies on lymphocytes in adult human bone marrow II. Isolated surface IgMpositive cells. J Immunol 1979:122:285-90.

Correspondence to Dr David Isaacs, Department of Paediatrics, John Radcliffe Hospital, Headington, Oxford OX3 9DU.

Received 12 November 1983

\title{
Effect of exogenous surfactant on total respiratory system compliance
}

\author{
A D MILNER, H VYAS, AND I E HOPKIN
}

Department of Neonatal Medicine and Surgery, City Hospital, Nottingham

SUMMARY We measured total respiratory system compliance (Crs) before and after instilling $25 \mathrm{mg}$ artificial surfactant in $1 \mathrm{ml}$ saline down the endotracheal tube of preterm babies requiring resuscitation at birth, and compared results with data from 6 similar babies receiving saline only. Surfactant did not produce a significant improvement in Crs.

The role of exogenous surfactant in prevention and treatment of idiopathic respiratory distress syndrome (IRDS) remains controversial. Giving surfactant, derived from either animal lungs ${ }^{1}$ or human amniotic fluid, ${ }^{2}$ to a small number of babies requiring ventilatory support for IRDS, led to dramatic improvement in blood gas values. The improvement could however be due to the relatively large volumes of fluid instilled down the endotracheal tube or to the period of manual ventilation by bag using $100 \%$ oxygen. In a recent study, we were unable to show any improvement in either compliance or blood gases when artificial surfactant was insufflated down the endotracheal tube of 10 similar babies. ${ }^{3}$ On the other hand, Morley et $a l^{4}$ reported trial results suggesting that surfactant powder instilled down the endotracheal tube of preterm babies requiring resuscitation at birth led to a significant reduction in mortality. This finding was not, however, confirmed by Wilkinson et al in a controlled trial on a small number of babies. ${ }^{5}$ To resolve this question we have been carrying out a controlled trial in conjunction with Dr Morley and his colleagues to assess the prophylactic value of instilling artificial surfactant $\quad(70 \%$ dipalmitoylphosphatidylcholine and $30 \%$ unsaturated phosphatidylglycerol) into the upper airways of preterm babies at birth. We report here the results of compliance measurements obtained before and after the instillation of placebo or surfactant in babies who failed to breathe spontaneously and required intubation.

\section{Methods}

Fifty eight babies born with a gestational age of less than 34 weeks were included in the main study. 